\title{
PRESAGIO, VENGANZA Y JUSTICIA: TRATADO SOBRE LOS BUITRES DE NIALL BINNS
}

\author{
OMEN, REVENGE AND JUSTICE. \\ TRATADO SOBRE LOS BUITRES BY NIALL BINNS
}

Clara María Parra Triana

Pontificia Universidad Católica de Valparaíso. Valparaíso, Chile. clara.parra@ucv.cl

\begin{abstract}
Ilbert Durand señala en sus Estructuras antropológicas del imagina-

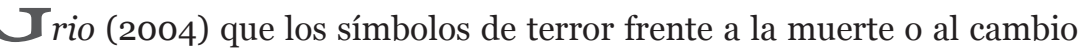
son en su gran mayoría animales que devoran: serpientes, monstruos híbridos, lobos, hienas, todos ellos encarnaciones demoníacas de lo negativo, de las tinieblas. Dentro de esta fauna nefasta, nos dice Durand, el pájaro suele ser un "mensajero benéfico" y solo en unos pocos y contados casos se le asocia a las fauces mutilantes. Los pájaros se movilizan dentro de nuestro imaginario ya sea por la gracia de su vuelo o por la atracción de su plumaje. La cinesis del vuelo hace del ave una especie mediadora entre lo humano (terreno) y lo divino (celestial); el espectáculo de su plumaje se entrega a los ojos humanos como un regalo de los dioses para apreciar la plenitud del mundo. Sin embargo, y pese a todos los motivos del ave en los estudios de antropología, historia de las religiones y psicología, existe un pájaro que no logró clasificar -no en Occidente- dentro de la ornitología divina y que es, sin más, la encarnación de la negatividad: el buitre, ave que por su asociación con la muerte, el hambre, el deseo, la saciedad y el miedo, ha perdido la simbología benéfica de su vuelo y de su plumaje y que ha sido el centro de la poética del escritor británico Niall Binns (1965)².
\end{abstract}

${ }^{1}$ Niall Binns es, además, uno de los más importantes estudiosos de la poesía chilena actual. Sobresalen sus trabajos sobre la poesía de Jorge Teillier, y sus lecturas del antipoeta Nicanor Parra. Sumado a esto, los años de aprendizaje del poeta Binns en Chile lo han hermanado con la producción poética contemporánea del país austral. 
Niall Binns investiga, lee y escribe en clave poética el desprecio y miedo occidental a lo que no se puede controlar por los medios de la razón, y encuentra en la imagen del buitre la posibilidad de realizar esa crítica poética que oscila entre la crueldad y la ternura; la ironía y el desencanto. Bajo la aparente forma del tratado, Binns explora en diversidad de mecanismos de expresión poética, con el fin de potenciar la significación del ave y apostar por otras formas de poesía.

Binns es uno de los grandes lectores actuales de la poesía en lengua española; pero es quizás la poesía chilena la que mejor acoge y respalda su trabajo con la palabra, pues como lo señala el poeta en su "Postdata" (2010) son Enrique Lihn, Jorge Teillier y Nicanor Parra, quienes le ofrecen un nuevo panorama de escritura y de pensamiento. Cuatro son sus obras de poesía: 5 Love songs (1999), 7 urracas (1999), Tratado sobre los buitres (2002) y Canciones bajo el muérdago (2003). En un par de intentos de revisión crítica de su obra, se han editado dos antologías poéticas (bajo la supervisión del autor) Oficio de carroñero (2006) y Salido de madre (2010). Pero es en Tratado sobre los buitres, obra que se comienza a escribir en el año '99 y que aún no concluye, en donde encontramos lo más elaborado de la poética del buitre 2 .

El Tratado sobre los buitres se encuentra dividido en seis grandes partes: la primera poetiza la terrible relación existente entre hombres y buitres, en la que los primeros desconocen la profunda hermandad que tienen con los segundos; luego entrega -a manera de escenas- la tipología de la estirpe carroñera: el buitre leonado, el buitre negro, el alimoche y el quebrantahuesos son héroes dentro de su propia lógica; la tercera parte, construida a partir de fragmentos de textos disímiles, es una exploración en el imaginario colectivo -mediatizado- con respuestas poéticas que se entrecruzan ficcionando la voz de los carroñeros; en la cuarta parte el buitre deviene poeta, y, las dos últimas partes -que se encuentran en la edición de 2011-, presentan al buitre como un vengador, en poética-hermenéutica

${ }^{2}$ Tratado sobre los buitres obtuvo el Premio Internacional de Poesía Gabriel Celaya en el año 2002. De allí hasta la fecha se ha reeditado dos veces. La segunda edición se reeditó en Argentina y prácticamente conserva el texto de la primera edición. La tercera edición de Chile incluye nuevos poemas compuestos desde el año 2002 hasta el año 2011. 
del ave sagrada en los funerales parsi, pues allí el buitre cumple la función de mediador entre la vida y la muerte, por último encontramos al carroñero escenificado en manifestaciones posmodernas de arte, en las que se presenta a manera de actor y objeto plástico.

El Tratado sobre los buitres se puede leer como una gran historia: es el relato del buitre y su desastre en manos de los hombres. Este puede ser un ensayo de las páginas que le faltan a la gran enciclopedia de los pájaros, o los marginalia que nunca fueron incluidos por innobles, por deshonrar a las bellas razas aladas que son vuelo y son gozo, pues en el imaginario popular se cree que "sólo se vuela en sueños cuando se es feliz" (Bachelard, 1993: 91), por lo que las metáforas del vuelo y de las alas del Tratado subvierten toda lógica de ensueño para entregar una crítica poética de la devastación.

He titulado esta nota "presagio, venganza y justicia", considerando estos tres motivos como la base del Tratado: el presagio, pues es el buitre quien adivina la cercanía de la muerte con sus olores y apariencias; la venganza, porque el carroñero usa sus propios medios para quitarse de encima la mirada inquisidora de los hombres; y la justicia, pues el ejercicio poético hace las veces de tribuna desde la que el ave se defiende.

\section{El presagio: Simbología del vuelo}

El presagio de la muerte que anuncia el vuelo del buitre es de una muerte truculenta, desgarrada, sangrienta y apestosa. El olor del buitre es el del aire mortecino y decadente. Vuelo y aire de muerte se conjugan metafóricamente para crear la imagen del buitre como la del ave del final tortuoso. Si la cinesis del vuelo en nuestro imaginario es la de la dicha, la plenitud, la libertad y la felicidad, en el vuelo del buitre que nos presenta el Tratado observamos su antítesis. El buitre no vuela, asecha; el buitre no canta, chilla; llama a la muerte con el batir de sus alas y se alimenta de sus restos. $\mathrm{El}$ asecho del buitre, su constante deseo de carroña, se puede apreciar en la peculiaridad de su vuelo, pues es una elevación para rodear al cuerpo moribundo que está a punto de convertirse en alimento. Este rodeo aéreo, a manera de danza colectiva, de conciliábulo del hambre, anuncia el deceso, el final inevitable. 
En la obra de Binns encontramos al hombre-buitre, y entendemos que la imagen maldita del ave es la metáfora de nuestra "pobre modernidad"; así los verdugos y asesinos, los que danzan sobre la muerte no son los buitres, es la humanidad rapaz y sangrienta, el hombre que no se sacia, que vive de la muerte y para ella:

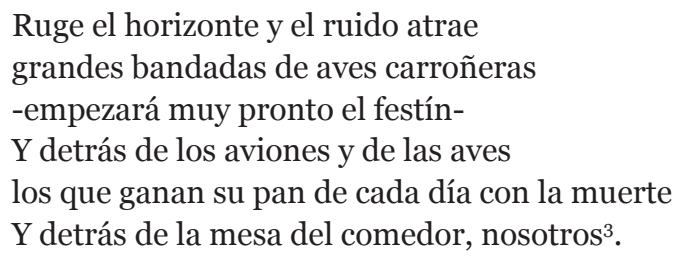

El hombre, carroñero cotidiano, ve desmembrarse su humanidad una y otra vez frente al televisor, mientras se come un buen pedazo de ternera, todavía sangrante. Puede alimentarse sin dificultad, mientras observa escenas de cadáveres y se lamenta cómodamente; sin embargo, apaga el televisor y continúa con su hambre cotidiana e insaciable.

El poema "Homo sapiens" cierra con el verso: "es una risa planetaria la nuestra”. Sí, nuestra risa es la de la hiena, la que nunca se harta, voraz y despreciable. Condenamos la muerte, pero la financiamos, pues iQué más dan unos cuantos aviones de guerra sobrevolando nuestras cabezas, mientras el hambre pueda saciarse!: "Carroñero él, carroñero yo".

El buitre es el otro, al que temo. Es la tercera persona, el que está lejos y fuera de mí y, por lo tanto, lo juzgo. Siempre es el otro el egoísta, el que saca partido, el que se aprovecha del débil -del moribundo-, siempre es el otro el que se ríe del que ha caído y le cae encima; de allí el poema “...y sin embargo...", texto fragmentario, compuesto con base en definiciones de diccionarios españoles e ingleses, en los que la fidelidad de la documentación contrasta con la lectura metafórica que se hace de ellos: "in a crisis, the vultures are always hovering" (14). El vuelo del buitre, del otro, es lento y

${ }^{3}$ Para la citación tomaré como referencia la primera edición del Tratado sobre los buitres (Alzira) Valencia, Editorial Germania, 2002. Sólo para los anexos de 2011 citaré directamente de la tercera edición de Santiago de Chile. 
sonoro. Su aleteo es dominante, sus enormes alas se doblan y dan grandes palmadas al aire para que lo anuncie. Desciende con el único fin de adueñarse de lo que le pertenece: el cuerpo que yace en la pradera. No importa si alguien más tiene hambre, la suya está primero.

\author{
Tras lánguidas horas de esperar \\ las corrientes templadas de las once \\ los buitres leonados \\ se lanzan al aire en busca de un muerto \\ Planean durante horas sobre montes y valles \\ y de pronto se detienen \\ concentran sus círculos: \\ fija la mirada telescópica en el borde \\ de un bosque donde brilla \\ a través del verde de las hojas \\ el resplandor rojizo del raposo agonizante
}

(Fragmento de "Cadena trófica/círculo vicioso", 26).

\title{
La venganza: simbología del hambre
}

Ya nos hemos acercado a la simbología del hambre que acompaña a la peculiaridad del vuelo de los buitres. Por ser este un rodeo asechante, la marca del deseo de su movimiento asemeja al apetito sin tregua. El hambriento es ante todo un ser deseante, sus sentidos convergen hacia el objeto de deseo: el alimento, el banquete. Todo el ser se vuelca metonímicamente hacia el gesto de la boca abierta, a la acción de hendir el pico en la presa que yace.

En el poema "Buitre" el significado del hambre explora otras salidas simbólicas, por lo cual se hermana al ave con otras creaturas devoradoras: los coleccionistas, los amantes, los sensacionalistas, los nostálgicos, los usureros, los eruditos, los adictos, entre otros. Al mismo tiempo el poema explora en el juego visual de la lengua española, a manera de caligrama. Inicia con un largo verso (verso-cadáver completo) y termina con una tautología breve (verso-restos). Al principio abundan las palabras para describir al carroñero; al final, y como en un acto digestivo, va disminuyendo la palabra, como disminuye el alimento bajo la bandada de aves devoradoras. 
Buitres somos todos, con nuestros hábitos modernos del ocio y del vacío. Nosotros en tanto seres deseantes, cargamos la condena del carroñero: la añoranza nostálgica de lo que no se tiene del todo.

Pero en esta poética el hambre hace parte de un ciclo vital y, en este sentido, la muerte y la vida son eventos contributivos, no excluyentes. La muerte del que yace se convierte en la posibilidad de vida de quien lo necesita; un ciclo inicia en donde el otro termina. El hambre es la prolongación de la vida en el plano ecológico-alimenticio, al mismo tiempo que se limpia el entorno, se preserva una especie. En el mismo plano de la contribución muerte-vida, el Tratado explora en la figura del buitre como ave sagrada en las culturas no occidentales. Contamos con dos encuentros de esta lectura poética del "morir es renacer": los poemas "Los hombres y los buitres" y "Las torres del silencio". Los primeros privilegian la figura del buitre como un mediador entre esta vida que termina y la que está por empezar; al descarnar los despojos mortales, el buitre limpia el mundo y contribuye al ascenso espiritual del difunto en la escala de la vida. Así lo leemos en "Ceremonia parsi, 2000 d. de J. C.": "Una celda de piedra en las torres del silencio/ Desnuda, la difunta está mirando hacia el Sur/Los pájaros descienden lentamente del cielo" (12).

$\mathrm{El}$ buitre mediador tiene otra imagen en "Funeral tibetano, $2000 \mathrm{~d}$. de J. C.”. En este poema el buitre ya no desgarra, él es alimentado por los enterradores con las partes del difunto. La corporeidad se elimina del mundo para evitar el regreso del hombre muerto. El cuerpo es acá señal del pasado que se quiere dejar atrás; el buitre transportará en su digestión al hombre en su ascenso por las escalas de la vida, la función del buitre se consolida en su carácter de 'ecólogo espiritual'.

En el poema "Las torres del silencio", el silencio es el de los buitres. Estos se han ido y los muertos se han quedado sin mediador. El caos ecológico de los parsis es inevitable. Las razas de buitres no se renuevan y los muertos crecen cada día: "en torno a las torres del silencio el silencio// se diría que es sepulcral” (2011: 91). Podríamos decir, para cerrar parcialmente, que la venganza de los buitres es su desaparición, pues si ellos se ausentan del mundo, la cadena trófica se rompe y el exceso de carroña nos cubrirá la garganta. 


\title{
Lajusticia: La palabra poética como tribuna
}

Como buen tratadista, Binns investiga desde diferentes ángulos la voz del buitre. Desde los diccionarios, pasando por los periódicos y los ensayos de ecología, el poeta reconstruye la pluralidad de perspectivas que asechan al temerario papel del buitre. En los poemas de "Y cuando el buitre se hizo matador", como lectores atestiguamos el contrapunto entre las voces acusadoras (calumniadoras) y la voz que insiste en su inocencia:

\author{
"Los buitres leonados sorprenden a la ciencia" \\ ¿Quién es más carroñero: \\ el buitre leonado o los que se aprovechan \\ de los sucesos aislados para reclamar \\ la desprotección de una especie amenazada? \\ Hay que tomar con la mayor urgencia \\ medidas en contra de los buitres predadores (50).
}

En este episodio, la poesía le presta su voz al buitre para que ejerza su derecho a la defensa. Los acusadores son sin lugar a dudas, los hombres, los sistemas, los medios masivos, la ciencia, el miedo. Todos estos discursos se pronuncian al unísono para señalar con el dedo a las aves, culpándolas de lo que de forma natural serían incapaces de hacer. Los poemas se construyen con base en hipótesis, y estas a su vez se presentan como posibilidades de acción. Ser un buitre en el mundo moderno es estar condenado a una competencia voraz, pues carroñeros hay muchos, cambian de forma para colarse en la sociedad, y desde sus trajes respetables de científicos y periodistas (voces del poema) ajustan el sentido de los hechos para salir beneficiados.

En esta sección del Tratado encontramos una reconstrucción irónica de los procedimientos científicos que funcionan con base en hipótesis; acá éstas devienen poemas, para luego proceder al experimento absurdo de ponerse en bandeja para los buitres. El sentido de las hipótesis juega tanto con el intertexto científico como con el jurídico. Los poemas "Hipótesis 1: carne viva", "Hipótesis 2: ¿todo es entonces un montaje?” e "Hipótesis 3: El mundo al revés", simulan la voz del buitre y la de sus acusadores; en ellos hay un esfuerzo de apelación, un despliegue de razones, una incursión en 
la conciencia del ave que, siendo ficticia, logra mostrar la enorme distancia existente entre nuestra lógica carroñera y el deseo de subvertir lo cotidiano, la costumbre, la rutina:

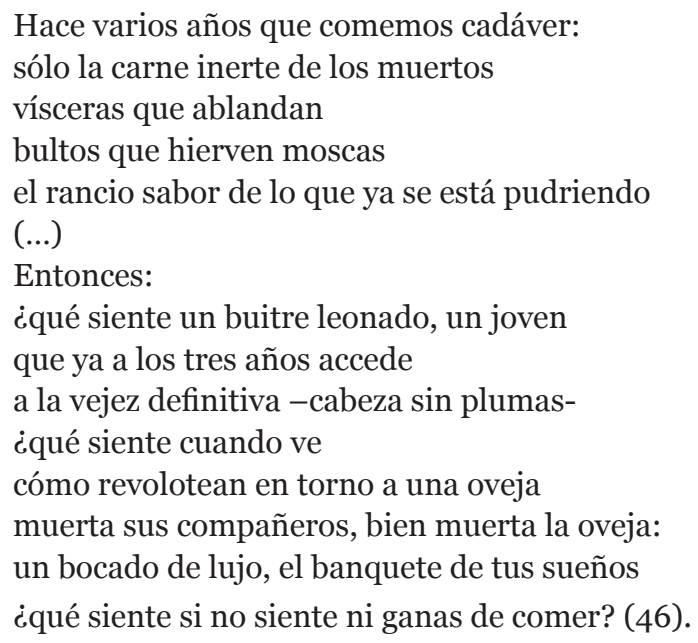

La fuerza de la individualización, los excesos de control, las formas disimuladoras de las democracias, la defensa de los derechos por sobre los procesos naturales, los abusos de la ciencia y la tecnología en nombre de un altruismo de dudosos mecanismos de acción, la diversión decadente, los castigos tortuosos, todo ello es controvertido en el Tratado bajo el cuestionamiento de ¿̇cómo hacer justicia frente al hambre generalizada que parece controlarlo todo?

El Tratado presenta un ajuste de cuentas del buitre con sus calumniadores. Los poemas de "La venganza del buitre" (2011) son composiciones que reconstruyen el origen de la maldición y recrean una suerte de justicia poética en la que el ave -desde sus procedimientos naturales- venga los señalamientos de siglos culposos:

¿Quién inventó la mentira?

¿Quién instaló al buitre en el bestiario del mal?

(...)

Pero ¿quién inventó la calumnia?

¿Quién fue el primero? 
¿Quién encarnó en la piel del buitre el mal?

(...)

¿Fuiste tú Esquilo? (58-59).

En respuesta a estas preguntas se despliega el poema "La calvicie de Esquilo" cuya composición juega con las fuentes de autoridad literarias y el discurso científico-ecológico, mediante la reconstrucción ficcionalizada de la venganza de los buitres (del quebrantahuesos) contra la cabeza de Esquilo: "La calvicie de Esquilo/ La calva de Esquilo, piedra arenisca/ en el páramo rocoso de la meseta siciliana/ En su calva está inscrito el destino" (61).

La cabeza de Esquilo, metonimia del juego imaginativo que labró varias condenas (las de sus personajes y la suya propia) es el blanco de la venganza; por su culpa, por su calvicie pensante, que no alcanzó a prever lo que le traía el destino en forma de tortuga, muere el poeta "en el páramo de la meseta siciliana" -quizá para banquete de los buitres. Esquilo supo, adivinó y trazó el destino de muchos, presagió el destino de muchos, en sus letras la venganza está a la orden del día y la justicia que corre tras sus personajes lo alcanzó a él ipobre carroñero de las fábulas trágicas!, "carroñero él, carroñero yo": "El caparazón se quebranta en una roca/ Cede la armadura, la carne se palpará/ Entre las rocas del páramo/ El cráneo de Esquilo es otra roca más" (63).

El humorismo de este poema, cargado de irreverencia y lucidez, nos muestra el revés del mito. El oráculo presagia, de manera burlesca, un destino poco heroico para el autor de tantos dramas auténticos y conflictos trascendentales. El poeta termina sus días de manera un tanto ridícula pero a la vez genial por lo que tiene de desmitificadora: que a un quebrantahuesos le falle la vista y le estrelle una tortuga dura hasta anularlo, más parece un final picaresco que el final de un hombre que vivió bajo el cielo estrellado de la épica o bajo el amplio firmamento de la tragedia.

\section{Nota sobre la escritura: El poema como cadáver}

Para Binns, el poeta se comporta como un carroñero y su escritura tiene la morfología del cadáver que se va tragando lentamente. Poetizar será enton- 
ces un proceso digestivo, doloroso y espectacular, en el que la saciedad no se alcanza, pues justamente ese vacío que queda es la posibilidad de seguir creando. El poeta hiende el pico (la pluma) en el cadáver de su escritura $\mathrm{y}$, con el detalle del artesano va deglutiendo presa a presa para generar la imagen deseada, nunca terminada: "lo ingerido se expresa y se expulsa/ lo expulsado se ingiere y se procesa/ pero el que lo procesa es prescindible" (65).

\author{
De pie en el vertedero \\ el buitre aletea su impotencia \\ (...) \\ El vertedero es el paraíso del olvidado; el buitre \\ -ave sagrada de otros tiempos- \\ pasea a trompicones, se le pudren las alas \\ jadea como un asmático \\ y sigue alimentándose con furia (65).
}

Irónicamente podríamos preguntarle al poema ¿Es esta el ave sagrada? Y si lo es ¿̇qué es entonces lo profano, lo decadente? El canto del ruiseñor o el vuelo de la golondrina abandonaron ya este mundo de palabras y dejaron en su lugar al buitre; para que la situación sea aún más grave éste se muere lentamente; nos estamos quedando sin símbolos, avanzamos hacia la pérdida inevitable. Así lo leemos en "Vocación de carroñero", poema de tema erótico que es la síntesis de todo el poemario: auge y caída, vuelo y torpeza en el caminar, putrefacción después del deseo, carne y sangre seca, reiteraciones y murmullos, restos de lo que no será más: "No la emoción en sí/ sino el cadáver de las emociones/ no la plenitud del amor sino su pérdida" (66).

Cierro esta reflexión en torno al Tratado sobre los buitres deteniéndome en el poema "Carroña de carroñas. Vulture Restaurant", que fue escrito con base en una puesta en escena de la fotógrafa Greta Alfaro (s/f). El poema comienza con un extenso epígrafe en el que se describen los mecanismos modernos para "conservar" a los buitres: facilitarles la comida mediante "restaurantes" de carroña, puestos calculadamente. De forma literal dice el epígrafe: "antes los restos eran impredecibles tanto en el espacio como en el tiempo" (before, carcasses were unpredictable both in space and time) (81), lo cual es un reproche, pues justamente el carácter impredecible 
tanto de la muerte como de la aparición del carroñero era lo que caracterizaba el proceso: "Now, however, carcasses have become aggregated and predictable both in space and time" (81).

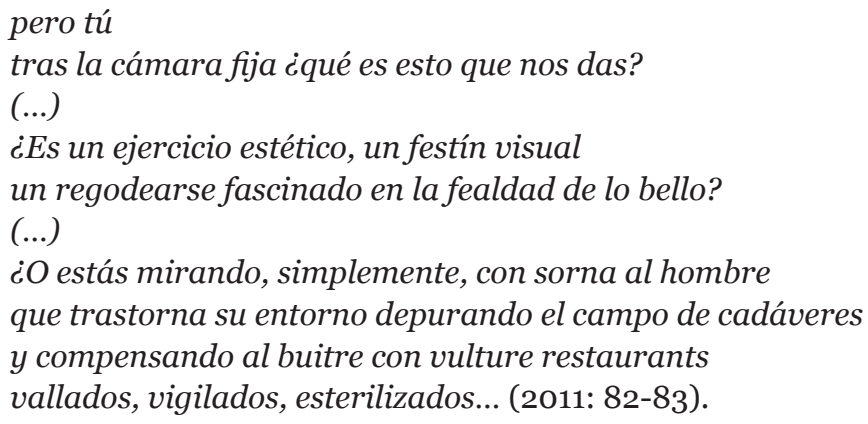

El intervencionismo posmoderno, las ganas de limpiarlo todo, son formas culpables que tiene el hombre de disimular la barbarie. Canibalismo desinfectado, ordenado, controlado, en un horario establecido, en una cantidad establecida. Saquemos a los buitres de la escena y la carroña nos llegará hasta la garganta.

\section{Referencias}

Alfaro, G. In IctuOculi. (s/f). Disponible en http://gretalfaro.blogspot.com/ search/label/2009\%20\%20In\%20Ictu\%20Oculi.\%20\%20

Bachelard, G. (1993). El aire y los sueños. Ensayo sobre la imaginación del movimiento. Ciudad de México: F.C.E.

Binns, N. (2002). Tratado sobre los buitres. (Alzira) Valencia: Editorial Germania (Primera edición). . (2010). Salido de madre. Antología poética. Santiago de Chile: Editorial Pfeiffer.

- (2011). Tratado sobre los buitres (Incluye anexos 2011). Santiago de Chile: Piedra de Sol Ediciones.

Durand, G. (2004). Las estructuras antropológicas del imaginario. Introducción a la arquetipología general. Ciudad de México: F.C.E. 